\section{Cureus}

Received 02/14/2018

Review began 02/15/2018

Review ended 03/05/2018

Published 03/08/2018

\section{C) Copyright 2018}

Robles et al. This is an open access article distributed under the terms of the Creative Commons Attribution License CC-BY 3.0., which permits unrestricted use, distribution, and reproduction in any medium, provided the original author and source are credited.

\title{
Brain Stem Ischemic Stroke Associated with Anaphylaxis
}

\author{
Luis A. Robles ${ }^{1}$, Antonio F. Matilla ${ }^{2}$ \\ 1. Section of Neurosurgery, Hospital Cmq 2. Section of Internal Medicine, Hospital Cmq \\ $\square$ Corresponding author: Luis A. Robles , larob@prodigy.net.mx \\ Disclosures can be found in Additional Information at the end of the article
}

\section{Abstract}

Anaphylaxis is a serious allergic reaction that may have different manifestations including hypotension. It is reported that vertebral artery hypoplasia (VAH) may be present in up to $20 \%$ of the general population. Previous studies have demonstrated that patients with VAH have a higher risk of developing an ischemic stroke in the area supplied by this hypoplastic artery. This paper describes the case of a patient with preexistent VAH who presented with lateral medullary syndrome associated with a hypotensive episode secondary to anaphylaxis. To the best of the authors' knowledge, this association has not previously reported.

Categories: Internal Medicine, Neurology, Allergy/Immunology

Keywords: lateral medullary syndrome, wallenberg syndrome, ischemic stroke, anaphylaxis

\section{Introduction}

Anaphylaxis is a serious, systemic, and life-threatening allergic reaction which most commonly is caused by foods, insect stings, and medications. Anaphylaxis is rapid in onset and it is characterized by respiratory and circulatory dysfunction, and usually associated with cutaneous and mucosal changes [1]. Anaphylaxis may be lethal when the circulatory and respiratory systems are severely compromised. In these patients, when death occurs, it is usually the result of shock.

Congenital variations in the size of the vertebral arteries are frequently observed in the normal population; this variation may range from asymmetry to severe hypoplasia of one vertebral artery. Previous reports suggested that HVA is considered when the diameter of the vertebral artery is less than 2-3 mm. A study by Park et al. showed a high incidence of VAH in patients with posterior circulation strokes [2]. In this study, $51 \%$ of patients with vertebral artery territory stroke showed ipsilateral VAH, which was too high compared to the control group, in which VAH was observed in $26 \%$ of cases. In another paper, Thierfelder et al. studied the perfusion in the PICA territory in cases of VAH. This study showed that VAH can lead to hypoperfusion in the area supplied by this artery [3]. More studies have demonstrated the same findings [4-5].

This paper presents the case of a patient who experienced a lateral medullary syndrome caused by an ischemic stroke which was associated with anaphylaxis. To the best of the authors' knowledge, cases like this have not been previously described.

\section{Case Presentation}

This is a 55 -years-old male, with no significant past medical history. His condition started after 


\section{Cureus}

eating a salad in a restaurant. He mentioned that he had eaten the same salad several months before and experienced a mild allergic reaction, he thought that the ingredient causing the allergy was the dressing. Several minutes after eating this food, he felt several symptoms suggestive of an allergic reaction including itchy and watery eyes, sneezing, runny nose, cough and trouble breathing. On admission, he was reported hypotensive with a blood pressure of 80/40 mmHg. He was started on intravenous fluids, steroids, and antihistaminics. One hour later; he experienced dizziness, vomiting, diplopia, difficulty in swallowing, and tingling on the right limbs.

On initial examination, he was alert, oriented, and presented with slight dysarthria. The patient's bilateral eye movements were normal. The patient presented with left Horner syndrome which included partial ptosis and miosis. In addition, the patient demonstrated left paresis of the palate. Motor function was normal in upper and lower extremities. Myotatic reflexes were normal. The patient demonstrated decreased sensation to pain and temperature to the right upper and lower extremities. An initial computed tomography (CT) scan was performed which was normal. The next day, a magnetic resonance imaging (MRI) was ordered that showed a left lateral medullary ischemic stroke (Figure 1).
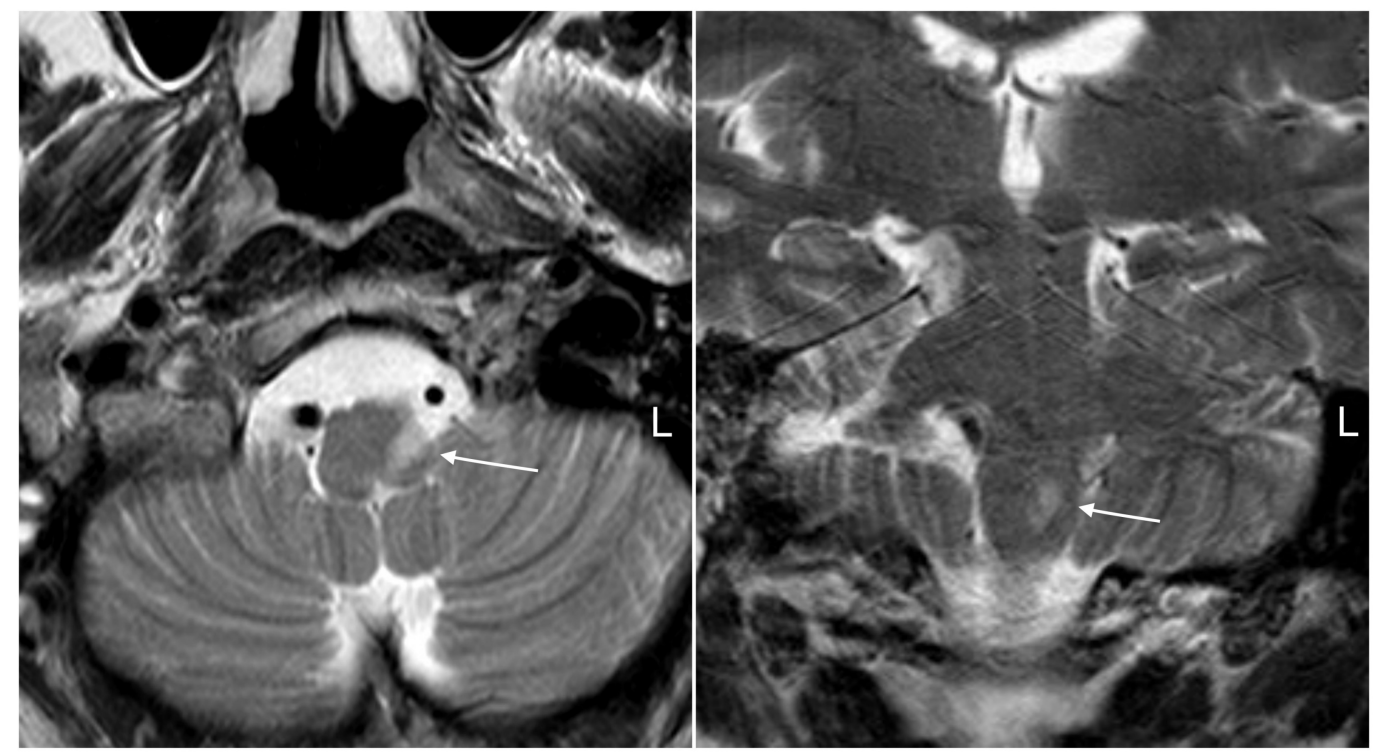

\section{FIGURE 1: Brain magnetic resonance imaging (MRI)}

Left: T2 sequence axial MRI displays a hyperintense area located in the left lateral medullary area (arrow). Note the diameter difference between both the vertebral arteries.

Right: T2 sequence coronal showing the same finding.

An angio-CT scan was then performed to evaluate the status of the vertebral arteries. This test displayed asymmetry of vertebral arteries due to hypoplasia of the left artery (Figure 2). 


\section{Cureus}

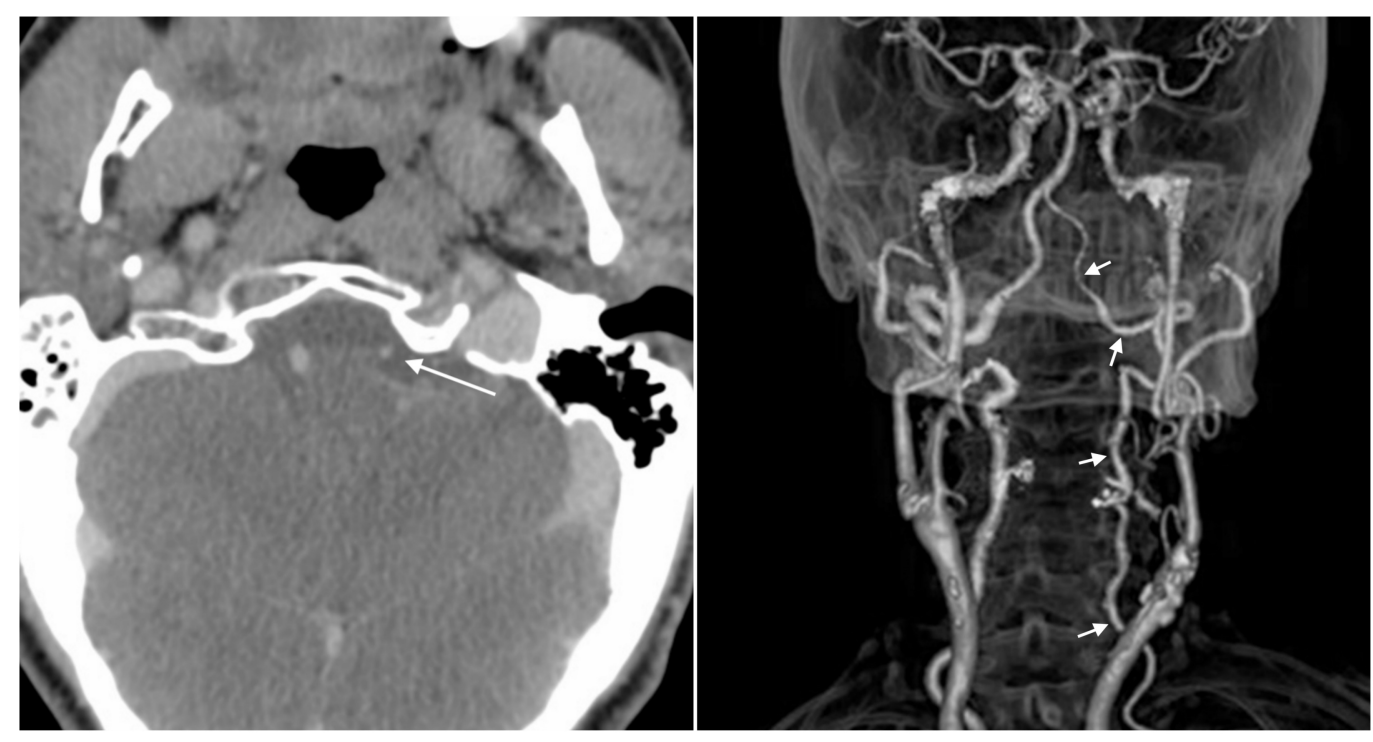

\section{FIGURE 2: Computed tomography (CT) angiogram}

Left: Contrast CT scan showing the small diameter observed in the left vertebral artery (arrow).

Right: CT 3D reconstruction displaying a hypoplastic left vertebral artery. This finding is observed from the origin of this artery (arrows).

The patient was discharged with medical treatment with clopidogrel and was sent to rehabilitation. One year later, he still experiences mild swallowing difficulty. In addition, he refers the presence of intermittent burning sensation on the right limbs which is being treated with gabapentin.

\section{Discussion}

Lateral medullar syndrome (Wallenberg syndrome) usually causes a constellation of neurological signs either contralateral (trunk and extremities hypalgesia and thermoanesthesia) or ipsilateral (facial hypalgesia and thermoanesthesia; palatal, pharyngeal and vocal cord paralysis; Horner syndrome; cerebellar signs). It results from ischemia to the lateral medullary area most often caused by the intracranial vertebral artery or posterior inferior cerebellar artery occlusion.

It is reported that congenital asymmetry and hypoplasia of one of the vertebral arteries can be observed in up to $25 \%$ of healthy people [2]. In addition, it has been described that the patients with a hypoplastic vertebral artery have a higher risk of having an ipsilateral stroke in the territory of this artery [2]. In these cases, the propensity to ischemic stroke is higher because the blood flow through the hypoplastic artery is less than normal.

A percentage of patients with anaphylaxis can present with cardiovascular manifestations including tachycardia and hypotension. It is reported that approximately $20 \%-30 \%$ of patients with anaphylaxis may experience hypotension [6]. Some studies have reported patients who developed brain ischemia after bee stings [7-9] suggesting a mechanism of hypotension related to anaphylaxis as probable cause; however, it seems that the mechanism of stroke is very different. Bee venom itself contains histamine, thromboxane, leucotrienes, and other vasoactive and inflammatory mediators [7]. In addition, a neuropharmacological (sympathetic) mechanism of endothelial permeability involving the cerebral vasculature with a concurrent systemic thrombogenic has been suggested [8-9]. All this information suggests that brain 
ischemia secondary to bee stings has a different pathophysiology than that observed in our case.

In the current case, the hypotension caused by anaphylaxis very probably was an important factor that led to brain stem regional ischemia in the setting of preexistent ipsilateral VAH. The fact that the stroke occurred in a very specific territory supplied by a direct arterial branch of the hypoplastic vertebral artery strongly suggest this scenario.

VAH is a congenital anomaly which normally is asymptomatic. The presence of this condition is usually an incidental finding in patients with ischemic stroke when additional radiological tests are performed. Therefore, treating physicians can do little to change the presence of a preexistent vascular anatomical variant.

\section{Conclusions}

This case shows that patients with hypotension secondary to anaphylaxis may have a higher risk of stroke, especially if a preexistent anatomical variation like VAH is present.

Unfortunately, because VAH is a congenital anomaly, it is usually diagnosed after an ischemic stroke has occurred. Physicians treating these patients must be aware of this scenario.

\section{Additional Information}

\section{Disclosures}

Human subjects: Consent was obtained by all participants in this study. Conflicts of interest: In compliance with the ICMJE uniform disclosure form, all authors declare the following:

Payment/services info: All authors have declared that no financial support was received from any organization for the submitted work. Financial relationships: All authors have declared that they have no financial relationships at present or within the previous three years with any organizations that might have an interest in the submitted work. Other relationships: All authors have declared that there are no other relationships or activities that could appear to have influenced the submitted work.

\section{References}

1. Reber LL, Hernandez JD, Galli SJ: The pathophysiology of anaphylaxis. J Allergy Clin Immunol. 2017, 140:335-348. 10.1016/j.jaci.2017.06.003

2. Park JH, Kim JM, Roh JK: Hypoplastic vertebral artery: frequency and associations with ischaemic stroke territory. J Neurol Neurosurg Psychiatry. 2007, 78:954-958. 10.1136/jnnp.2006.105767

3. Thierfelder KM, Baumann AB, Sommer WH, et al.: Vertebral artery hypoplasia: frequency and effect on cerebellar blood flow characteristics. Stroke. 2014, 45:1363-68. 10.1161/STROKEAHA.113.004188

4. Chen YY, Chao AC, Hsu HY, Chung CP, Hu HH: Vertebral artery hypoplasia is associated with a decrease in net vertebral flow volume. Ultrasound Med Biol. 2010, 36:38-43. 10.1016/j.ultrasmedbio.2009.08.012

5. Chuang YM, Chan L, Wu HM, Lee SP, Chu YT: The clinical relevance of vertebral artery hypoplasia. Acta Neurol Taiwan. 2012, 21:1-7.

6. Brown AF, McKinnon D, Chu K: Emergency department anaphylaxis: a review of 142 patients in a single year. J Allergy Clin Immunol. 2001, 108:861-6. 10.1067/mai.2001.119028

7. Riggs JE, Ketonen LM, Bodensteiner JB, Benesch CG: Wasp sting-associated cerebral infarction: a role for cerebrovascular sympathetic innervation. Clin Neuropharmacol. 1993, 16:362-365.

8. Rajendiran C, Puvanalingam A, Thangam D, et al.: Stroke after multiple bee sting. J Assoc Physicians India. 2012, 60:122-4.

9. Riggs JE, Ketonen LM, Wymer JP, Barbano RL, Valanne LK, Bodensteiner JB: Acute and 


\section{Cureus}

delayed cerebral infarction after wasp sting anaphylaxis. Clin Neuropharmacol. 1994, 384-388. 